\title{
Family support programs and adolescent mental health: review of evidence
}

This article was published in the following Dove Press journal:

Adolescent Health, Medicine and Therapeutics

10 July 2014

Number of times this article has been viewed

\author{
Emily S Kuhn \\ Robert D Laird \\ Department of Psychology, \\ University of New Orleans, \\ New Orleans, LA, USA
}

Correspondence: Robert D Laird Department of Psychology, GP 200I, University of New Orleans,

New Orleans, LA 70148, USA

$\mathrm{Tel}+\mathrm{I} 5042805454$

Fax +I 5042806349

Email rlaird@uno.edu

\begin{abstract}
Family support programs aim to improve parent wellbeing and parenting as well as adolescent mental and behavioral health by addressing the needs of parents of adolescents experiencing or at risk for mental health problems. Family support programs can be part of the treatment for adolescents diagnosed with mental or behavioral health problems, or family support programs can be delivered as prevention programs designed to prevent the onset or escalation of mental or behavioral health problems. This review discusses the rationale for family support programs and describes the range of services provided by family support programs. The primary focus of the review is on evaluating the effectiveness of family support programs as treatments or prevention efforts delivered by clinicians or peers. Two main themes emerged from the review. First, family support programs that included more forms of support evidenced higher levels of effectiveness than family support programs that provided fewer forms of support. Discussion of this theme focuses on individual differences in client needs and program adaptions that may facilitate meeting diverse needs. Second, family support prevention programs appear to be most effective when serving individuals more in need of mental and behavioral health services. Discussion of this theme focuses on the intensity versus breadth of the services provided in prevention programs. More rigorous evaluations of family support programs are needed, especially for peer-delivered family support treatments.
\end{abstract}

Keywords: intervention, parent, mental and behavioral health

\section{Introduction}

Many prevention and treatment approaches that have demonstrated effectiveness in promoting adolescent mental and behavioral health are family-centered. ${ }^{1}$ The effectiveness of family-centered programs suggests the importance of family factors in contributing to and protecting against adolescent behavioral and emotional problems. Family-centered inventions are often implemented as support programs, and family support programs will be the focus of this review. Family support programs aim to improve parent wellbeing, parenting, and adolescent mental and behavioral health by addressing the needs of parents of adolescents with mental health problems ${ }^{2}$ or at risk for mental health problems.

In this review, we first discuss the rationale for providing family support programs in adolescent mental health. Next, we provide an overview of the common components of family support programs in adolescent mental health and then discuss the modes through which family support programs are delivered. Evidence of the effectiveness of family support treatment and prevention programs is reviewed for several different typologies based on components and delivery method. This review aims to 
complement the more detailed descriptions and reviews of specific programs that are available elsewhere. ${ }^{2,3}$

\section{Importance of and rationale for family support programs}

Approximately $20 \%$ of adolescents aged $12-17$ have mental health problems. ${ }^{4}$ Adolescents with mental health problems are more likely than other adolescents to engage in risky behaviors and to experience other negative consequences. ${ }^{5}$ Adolescent mental health problems also negatively affect adolescents' families. $^{4,6-9}$

According to ecological theories, ${ }^{10}$ individual development occurs within the context of multiple progressively larger socialization spheres. The central sphere of influence is the everyday environment the person encounters - particularly the family. Broader systems of social institutions - which can include health services and family support programs - can affect the development and mental and behavioral health of the individual and the family. Family support programs can provide parents with the resources and support to effectively interact with their adolescents and perform their parenting responsibilities. ${ }^{10}$

Although poor family function is not required for adolescents to experience mental health problems, and adolescent mental health problems do not inevitably lead to family dysfunction, poor family functioning is robustly linked to poor adolescent mental health. Adolescents' mental health problems place a burden on families and can be a source of family distress. ${ }^{4,6-9}$ Higher levels of parental psychopathology, higher levels of parental stress, poor parenting practices, higher levels of parent-adolescent conflict, and lower levels of perceived family support are linked with higher levels of adolescent emotional, social, and behavioral problems. ${ }^{7,8,11-15}$ The link between family functioning and adolescent mental health is likely bidirectional and transactional. In any given family, poor family functioning may initially be a contributor to or consequence of poor adolescent mental health. However, over time, the two are likely to become linked through numerous transactions such that worsening mental health problems undermine family functioning and worsening family functioning exacerbates adolescent mental health problems. Regardless of whether family distress is a contributor to or consequence of adolescent mental health problems, family support programs have the potential to improve adolescent mental health by reducing family distress.

In line with ecological theories, family support programs acknowledge the impact of the family on the development of adolescents with mental and behavioral health problems and recognize that families need support. The goals of family support programs are to reduce both the adolescents' mental health problems and the adverse consequences of adolescents' mental health problems experienced by families. As such, impacts on parents and adolescents both provide evidence of the effectiveness of family support programs.

\section{Characteristics of family support programs}

Family support programs differ in program delivery method, in whether the program seeks to function as a prevention or treatment program, and in program characteristics. Family support programs may be delivered by either professionals, parent peers, or by a professional/peer team. ${ }^{2}$ Clinician-led models are typically delivered by master's or doctoral-level clinicians and psychologists, ${ }^{2}$ but they may also be delivered by school personnel such as teachers. ${ }^{3}$ Peer-led programs are provided by parents or veteran parents to parents or caregivers. ${ }^{2}$ Team-led models include a parent peer and a professional/clinician.

Prevention programs aim to reduce the likelihood of new cases of a disorder by altering underlying mechanisms implicated in the development and maintenance of the disorder. Prevention is distinct from - but complementary to - treatment in their common goal of reducing the burden of mental and behavioral health problems. ${ }^{16}$ Treatment occurs when an individual who suffers from a disorder receives services in order to experience relief from the disorder. ${ }^{16}$ Prevention services are offered to individuals who do not meet criteria for a disorder, but the goal is to reduce the likelihood of developing a disorder in the future. Given that treatment and prevention programs may differ in the populations they serve and in specific program goals and methods, evidence of the effectiveness of treatment and prevention programs will be reviewed separately.

Many family support programs share common components, which have been aggregated and organized into five major categories: instructional, informational, advocacy, emotional, and instrumental supports. ${ }^{2}$ These components distinguish family support programs from other family-centered services. ${ }^{17}$ Instructional support includes teaching parents skills to effectively manage their adolescent's behavior, engage in self-care practices including effective coping strategies, and effectively communicate with their family. ${ }^{2}$ Instructional support is designed to develop parents' skills for effective family management and for attending to personal wellbeing. Informational support includes the provision of information 
about mental health problems, intervention options, and adolescent development. ${ }^{2}$ The goal of informational support is to increase understanding of mental health problems to set the stage for treatment and better management of behavioral and mental health problems. Advocacy supportive services typically aim to empower parents by providing information about parental rights and resources and training parents in areas such as assertiveness, communication, goal setting, and record keeping, which can help parents advocate for their adolescent's services. ${ }^{2}$ Emotional support typically is provided via the opportunity to discuss issues, share experiences and insight in a group format. Some clinician-led family support programs provide the opportunity to discuss issues one-on-one with a clinician. ${ }^{18}$ Regardless of delivery format, the goal of emotional support is to enhance social connection and support, and to decrease feelings of isolation and helplessness. Instrumental support services incorporate broader supportive networks by linking families to concrete community-based resources such as childcare services, transportation services, and social services agencies. ${ }^{2}$ Encouraging families to utilize the natural resources of their communities is beneficial for maintenance of positive gains made while receiving family support services.

\section{Review criteria}

This review updates and synthesizes prior reviews, ${ }^{2,3}$ but concentrates on family support prevention and intervention programs delivered or evaluated with a focus on adolescence. Family support program evaluations with published outcome data relevant to mental and behavioral health and functioning were identified from previous reviews and by a literature search of studies published from 2009 to 2014 that cited previous reviews. We identified one new family support intervention ${ }^{19}$ and updated the findings for several programs with studies published since the earlier reviews. ${ }^{20-23}$

\section{Effectiveness of family support treatment programs}

Many family support programs combine one or more of the five components, but the particular combination of components varies as a function of how the support program is delivered. Most family support treatment programs are clinician-led. For this review, clinician-led programs were divided into three groups that differ in program components. Among clinician-led programs, the combination of instructional and informational support is most common with a second group of programs adding advocacy to instructional and informational support. The final group of clinician-led programs combines emotional support with either instructional or informational support. Clinician-led interventions that did not include one of the most commonly identified groupings of program components (eg, clinician-led programs with only one form of support, or with all forms of support) were excluded from this review. There were too few peer-led or team-led programs to further divide those delivery categories based on components. The sections that follow summarize the evidence of effectiveness of family support treatments for clinician-led, peer-led, and team-led delivery methods.

\section{Clinician-led with combined instructional and informational support}

The clinician-led family support programs included in this review are described in Table 1. The majority of clinician-led programs combined instructional and informational support. Caregiver outcomes included improvements in ${ }^{24,25}$ as well as null ${ }^{26}$ and non-superior effects on ${ }^{25}$ mental health and stress. Beneficial findings included improved parental self-esteem, more positive cognitions regarding the child, ${ }^{24}$ and increased participation $\mathrm{in}^{27}$ and satisfaction with the treatments. ${ }^{24,28}$

Regarding child outcomes, family support programs that combined instructional and informational components yielded benefits such as reductions in various symptoms of anxiety disorders at post-treatment and follow-ups. ${ }^{26,28}$ Two studies showed non-superior (ie, equivalent) effects on behavioral problems relative to non-family support comparison ${ }^{29}$ and control ${ }^{25}$ conditions. One study found that family support alone is as effective as combined family support and medication and medication alone conditions for ameliorating child internalizing problems. ${ }^{30}$ Additionally, family support programs with instructional and informational components were associated with superior effects on reducing child anxiety disorder diagnoses among children of parents with anxiety disorders. ${ }^{29,31}$

In sum, clinician-led programs that combined instructional and informational support yielded mixed results. Outcomes included some benefits on caregiver mental health and child internalizing problems, as well as some null and non-superior effects relative to comparison and control conditions. Evidence suggested that children at higher risk for anxiety - due to having parents with anxiety disorders may especially benefit from family support programs with instructional/informational components. ${ }^{29,31}$

\section{Clinician-led with combined instructional, informational, and advocacy support}

Clinician-led programs that combined instructional, informational, and advocacy support were the second most 






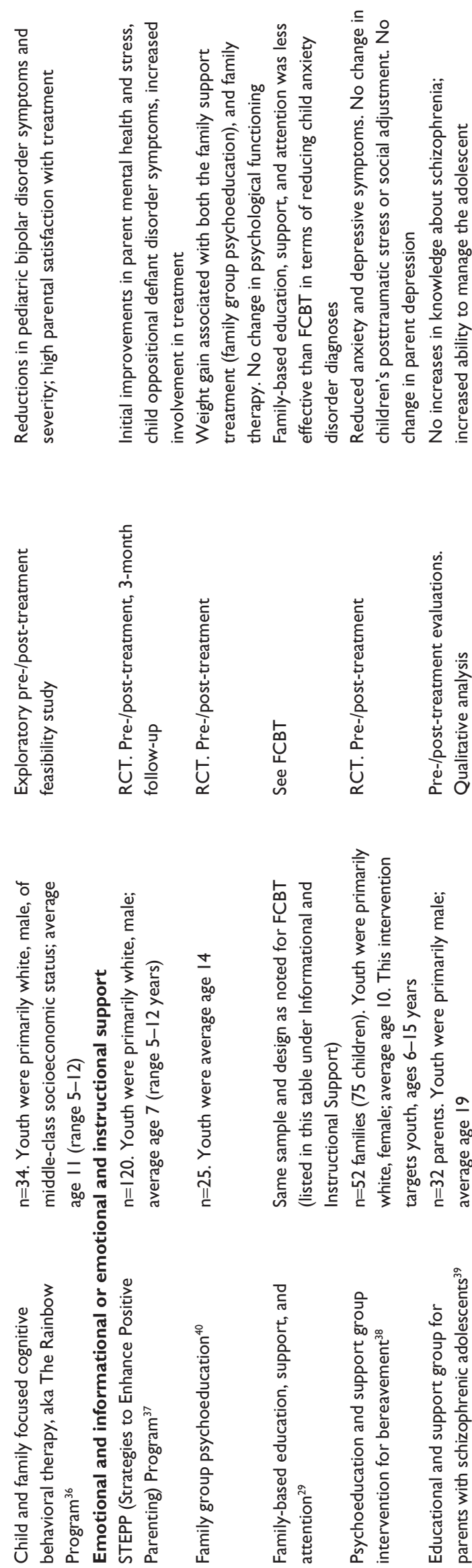

common type of clinician-led program. Among clinician-led programs that combined instructional, informational, and advocacy support, beneficial caregiver outcomes included reductions in distress, ${ }^{32,33}$ and aversive behavior ${ }^{34}$ as well as improvements in parenting skills,,$^{32,33,35}$ parenting confidence, ${ }^{35}$ and increased knowledge regarding the child's disorder. ${ }^{34}$ Additionally, some studies reported high levels of caregiver satisfaction with the treatment. ${ }^{34-36}$ Positive child outcomes included significant decreases in mental and behavioral health problems, ${ }^{32,33,35,36}$ reduced problematic cognitions, ${ }^{32,33}$ and increased parental social support. ${ }^{34}$ One study also reported high levels of child satisfaction with the treatment. ${ }^{34}$ Clinician-led programs that combined instructional, informational, and advocacy support yielded favorable results and were linked to improvements in caregiver's mental health, parenting knowledge and skills, as well as benefits for children's mental and behavioral health.

\section{Clinician-led with a combination of either emotional and instructional or emotional and informational support}

A minority of clinician-led programs included emotional support combined with either instructional or informational support. These programs were associated with null effects ${ }^{37}$ and initial improvements - that were not maintained at 3-month follow-up ${ }^{37}$ - on parental mental health. Although parents did not experience increased knowledge about the child's disorder, ${ }^{39}$ they exhibited increased involvement in treatment. ${ }^{38}$ Child outcomes were also mixed and included initial but nonmaintained improvements in behavioral problems, ${ }^{37}$ as well as reductions ${ }^{38}$ and null effects on mental health and social adjustment. ${ }^{38,40}$ Additionally, family support programs that combined emotional support with either informational or instructional support evidenced non-superior effects versus comparison non-family-support interventions in one study ${ }^{40}$ and weaker effects than a family support intervention that combined informational and instructional support. ${ }^{29}$ Evidence for clinician-led programs that emphasized emotional support combined with either instructional or informational support is mixed, with positive and null effects, as well as equivalency but non-superiority or weaker effects relative to a comparison nonfamily support intervention and a family support intervention with different combinations of support components.

\section{Peer-led}

Peer-led programs were the second most common family support service delivery model after clinician-led programs. ${ }^{2}$ The peer-led family support programs included in this review 
are described in Table 2. Caregiver outcomes included improved mental health ${ }^{23}$ and increased self-care, ${ }^{22}$ but one study found no differences in parental strain. ${ }^{41}$ One study reported enhanced knowledge regarding mental health and treatment, ${ }^{23}$ but another study reported no effect of the program on knowledge of community resources or court knowledge. ${ }^{19}$ Two studies reported increased caregiver empowerment, ${ }^{22,42}$ and one study reported no differences in caregiver empowerment. ${ }^{41}$ One program was more effective among highly strained parents. ${ }^{20,21}$ Other caregiver outcomes included improvements in select aspects of communication ${ }^{22}$ and treatment satisfaction. ${ }^{19,23}$ Peer-led programs yielded little to no evidence of effectiveness for youth's behavioral, emotional, and academic functioning. ${ }^{20,21,41,42}$ While veteran parents may serve as an important source of support for parents, ${ }^{2}$ there was inconsistent evidence of benefits from these programs for caregiver mental health and empowerment, and the effects on child functioning were largely null.

\section{Team-led}

Team-led programs were a relatively rare model of service delivery. Team-led family support programs included in this review are described in Table 3. Beneficial caregiver outcomes included increases in caregiver knowledge about mental health services and increased self-efficacy regarding the ability to acquire mental health treatment for the child. ${ }^{43}$ However, several studies reported no effect or non-superior effects of the team-led family support treatments relative to comparison treatments for parental outcomes such as caregiver involvement in the child's mental health services, parent problem-solving skills, coping skills, or perceived social support. In terms of child outcomes, one study showed reductions in child disruptive behavior, while another study showed nonsuperior effects of the team-led family support intervention relative to comparison treatment on child behavior. In sum, although team-led treatment studies showed some positive effects on caregiver outcomes, child outcomes were more mixed, and there was minimal evidence demonstrating the superiority of team-led family support programs over comparison treatments.

\section{Treatment effectiveness summary}

Overall, treatment effectiveness varied by service delivery model. Clinician-led and team-led models often were

Table 2 Peer-led programs

\begin{tabular}{|c|c|c|c|}
\hline Program, source & Sample demographics & Design & Relevant findings \\
\hline $\begin{array}{l}\text { Parent Empowerment } \\
\text { Program }^{41}\end{array}$ & $\mathrm{n}=124$ low-income minority parents & $\mathrm{RCT}$ & $\begin{array}{l}\text { No differences in parents' service self- } \\
\text { efficacy, empowerment, or strain. No } \\
\text { impact on child emotional or } \\
\text { behavioral functioning }\end{array}$ \\
\hline $\begin{array}{l}\text { EPSDT Family } \\
\text { Associate Program }{ }^{42}\end{array}$ & $\begin{array}{l}\mathrm{n}=239 \text { families. Youth were primarily } \\
\text { white, male; ages } 4-7 \text { years; from } \\
\text { households with annual incomes of less } \\
\text { than } \$ 10,000 \text {. This program targets } \\
\text { parents of youth, ages } 4-18 \text { years }\end{array}$ & $\begin{array}{l}\text { Quasi-experimental. Pre-/ } \\
\text { post-treatment }\end{array}$ & $\begin{array}{l}\text { Increased caregiver empowerment } \\
\text { concerning family issues and the } \\
\text { children's services. No changes in } \\
\text { child behavior problems }\end{array}$ \\
\hline Parent Connectors ${ }^{20,21}$ & $\begin{array}{l}\mathrm{n}=\mathrm{II} 5 \text { and } 128 \text {. Youth were primarily } \\
\text { male, black, of low socioeconomic } \\
\text { status; average age } \sim 14 \text { years }\end{array}$ & $\begin{array}{l}\text { I) Proof of concept study } \\
\text { using random assignment, } \\
\text { 2) RCT. Pre-/post-treatment }\end{array}$ & $\begin{array}{l}\text { Intervention more effective among } \\
\text { highly strained parents. Little to no } \\
\text { evidence of effectiveness for youth; } \\
\text { improved youth school functioning } \\
\text { but not academic functioning }\end{array}$ \\
\hline NAMI Basics Program²2 & $\begin{array}{l}\mathrm{n}=82 \text {. Youth were primarily male; } \\
\text { average age } 10 \text {; parents were primarily } \\
\text { white. NAMI Basics targets children } \\
\text { and adolescents }\end{array}$ & $\begin{array}{l}\text { Pre-/post-treatment } \\
\text { evaluations }\end{array}$ & $\begin{array}{l}\text { Improvements in parent } \\
\text { empowerment and self-care. } \\
\text { Reductions in inflammatory/incendiary } \\
\text { communication but no improvement } \\
\text { in positive/affirming communication }\end{array}$ \\
\hline $\begin{array}{l}\text { Juvenile Justice I0I } \\
\text { (JJ IOI })^{19}\end{array}$ & $\begin{array}{l}\mathrm{n}=\mathrm{I} \text { I I. Sample was primarily female, } \\
\text { and white-non-Hispanic. JJ IOI targets } \\
\text { juveniles }\end{array}$ & Post-treatment evaluation & $\begin{array}{l}\text { Most participants endorsed satisfaction } \\
\text { but denied increased knowledge of } \\
\text { community resources. No significant } \\
\text { effect on court knowledge }\end{array}$ \\
\hline $\begin{array}{l}\text { Screening, Education, } \\
\text { and Empowerment }{ }^{23}\end{array}$ & $\begin{array}{l}\mathrm{n}=24 \text {, but eight mothers (others were } \\
\text { peer advocates and supervisors). Youth } \\
\text { were primarily Hispanic, male; average } \\
\text { age } \sim 9 \text { years }\end{array}$ & $\begin{array}{l}\text { Feasibility study with post- } \\
\text { treatment evaluation }\end{array}$ & $\begin{array}{l}\text { Parents were primarily satisfied with } \\
\text { the intervention and perceived it as } \\
\text { relevant. Perceived benefits included } \\
\text { enhanced knowledge about depression } \\
\text { and treatment, and improvement in } \\
\text { mental health }\end{array}$ \\
\hline
\end{tabular}

Abbreviations: RCT, randomized controlled trial; EPSDT, Early and Periodic Screening, Diagnosis and Treatment Program; NAMI, National Alliance on Mental Illness. 
Table 3 Team-led programs

\begin{tabular}{|c|c|c|c|}
\hline Program, source & Sample demographics & Design & Relevant findings \\
\hline $\begin{array}{l}\text { Vanderbilt Caregiver } \\
\text { Empowerment }^{43}\end{array}$ & $\begin{array}{l}\mathrm{n}=250 \text { parents. Youth were primarily } \\
\text { male; ages } 6-17 \text { years, and parents } \\
\text { were primarily white }\end{array}$ & 3- and I2-month follow-ups & $\begin{array}{l}\text { Increased parental knowledge } \\
\text { and mental health services } \\
\text { self-efficacy; no effect on } \\
\text { involvement in treatment. No } \\
\text { effect on child mental health }\end{array}$ \\
\hline Multiple Family Group ${ }^{44}$ & $\begin{array}{l}\mathrm{n}=88 \text {. Youth were primarily black, } \\
\text { male; average age } 9 \text { years. The Multiple } \\
\text { Family Group program targets youth, } \\
\text { ages } 7-\text { I I years }\end{array}$ & Pre-/post-treatment evaluations & $\begin{array}{l}\text { Reduced child disruptive } \\
\text { behavior }\end{array}$ \\
\hline $\begin{array}{l}\text { Support, Empowerment } \\
\text { and Education Group } \\
\text { Intervention }\end{array}$ & $\begin{array}{l}n=94 \text { parents. Average age of youth } \\
\text { at intake was } \sim \text { I I years }\end{array}$ & $\begin{array}{l}\text { RCT. Baseline (intake), } 9 \text { months, } \\
\text { I } 8 \text { months (treatment duration was } \\
\text { a minimum of } 6 \text { months, and average } \\
\text { time for comparison condition was } \\
\text { I } 2 \text { months) }\end{array}$ & $\begin{array}{l}\text { No differences between the } \\
\text { family support intervention } \\
\text { and treatment as usual for } \\
\text { parent or child outcomes }\end{array}$ \\
\hline
\end{tabular}

Abbreviation: RCT, randomized controlled trial.

evaluated using experimental designs and, most importantly, randomized controlled trials. ${ }^{2}$ In contrast, peer-led programs were less rigorously studied, and the research evidence regarding their effectiveness was weak. Clinician-led programs yielded positive benefits on caregiver mental health, parenting knowledge, and parenting strategies, as well as improvements in child mental and behavioral health. However, there were also some null effects and lack of evidence of superiority of clinician-led programs relative to comparison/control conditions. Team-led treatments were associated with some benefits including increased empowerment and reductions in child disruptive behavior, but as with clinician-led programs there was minimal evidence demonstrating enhanced outcomes of team-led family support programs compared with comparison/control conditions. Peer-led treatment outcomes were mixed regarding effects on caregiver empowerment, and there were largely no effects on child functioning.

\section{Effectiveness of family support prevention programs}

Methods of prevention can be classified along four levels - universal, selective, indicated, or multilevel. ${ }^{3}$ Universal prevention programs - sometimes referred to as primary preventions - aim to reduce the incidence of new cases of disorder by preventing the onset of disorder. Selective prevention programs - sometimes termed secondary preventions - attempt to reduce the prevalence of disorders via early identification and aggressive treatment of subclinical problems. Indicated preventions intervene with individuals displaying symptoms of, but not meeting full diagnostic criteria for, mental and behavioral health disorders, and these prevention programs focus on minimizing further negative consequences. Prevention programs containing more than one prevention level are classified as multilevel preventions. ${ }^{3}$ When multilevel preventions are employed, universal interventions may serve as a screening mechanism, and individuals may be identified for more intensive prevention based on increased risk. Program components were quite similar across preventions - with nearly all prevention programs including instructional and informational elements - therefore, prevention programs are organized by levels of prevention (universal, selective, indicated, or multilevel) rather than by program components.

\section{Universal family support prevention programs}

Universal prevention programs often attempt to promote mental and behavioral health through education. Universal preventions are the second most common type of family support prevention program. ${ }^{3}$ The universal family support prevention programs included in this review are described in Table 4. Positive child outcomes include decreases in withdrawal, hyperactivity, sexual behavior problems, and oppositional and delinquent behaviors ${ }^{46-52}$ - however, there were some exceptions wherein programs did not have significant effects on problem behaviors. ${ }^{53,54}$ Youth in universal prevention programs experienced longer delays in the onset of involvement with antisocial peers, substance use, and arrests. ${ }^{51}$ While it is preferable to prevent rather than delay the incidence or onset, delaying onset is also important because it reduces the adverse impact of risky behaviors such as substance use by reducing the duration of them. Improvements in prosocial behavior such as increases in social competence were noted in some $\mathrm{e}^{47,50}$ but not other ${ }^{55}$ studies. Reductions in mental health problems such as anxiety and depression were also experienced among youth who participated in universal preventions. ${ }^{26,56-59}$ 
Table 4 Universal prevention programs

\begin{tabular}{|c|c|c|c|}
\hline Program, source & Sample demographics & Design & Relevant findings \\
\hline $\begin{array}{l}\text { Center for Improvement } \\
\text { of Child Caring Effective } \\
\text { Black Parenting Program } \\
(\text { EBPP })^{46}\end{array}$ & $\begin{array}{l}\mathrm{n}=109 \text { black families. EBPP has } \\
\text { been used with youth up to } \\
\text { age } 18 \text { years, but this study } \\
\text { included youth in first and } \\
\text { second grades }\end{array}$ & $\begin{array}{l}\text { Quasi-experimental. Pre-/post- } \\
\text { treatment, I-year follow-up }\end{array}$ & $\begin{array}{l}\text { Reduced child hyperactivity and } \\
\text { delinquency, reduced poor parenting } \\
\text { strategies and increased parental use of } \\
\text { praise }\end{array}$ \\
\hline FRIENDS $^{56,93}$ & $\begin{array}{l}\mathrm{n}=594 \text { and } 692 \text {. Youth were } \\
\text { primarily female; ages 9-16 }\end{array}$ & $\begin{array}{l}\text { RCT. Pre-/post-treatment, } \\
\text { I2-month follow-up }\end{array}$ & $\begin{array}{l}\text { Reduced anxiety, reduced depressive } \\
\text { symptoms only for FRIENDS participants } \\
\text { with high levels of anxiety at pre- } \\
\text { treatment. Initially, younger participants } \\
\text { experienced stronger effects }\end{array}$ \\
\hline $\begin{array}{l}\text { Home-based } \\
\text { Intervention }{ }^{57,58}\end{array}$ & $\begin{array}{l}\mathrm{n}=80 \text { families. Youth were } \\
\text { primarily female; assessed at } \\
\text { ages }|4-| 5,20-2 \mid\end{array}$ & $\begin{array}{l}\text { Systematic sampling, assignment } \\
\text { to intervention or control group; } \\
\text { I5-year and } 20 \text {-year post- } \\
\text { treatment follow-ups }\end{array}$ & $\begin{array}{l}\text { Reduced adolescent overall symptoms, } \\
\text { particularly internalizing rather than } \\
\text { externalizing symptoms. Intervention } \\
\text { was more effective among youth from } \\
\text { high-risk relative to low-risk families }\end{array}$ \\
\hline $\begin{array}{l}\text { Linking the Interests of } \\
\text { Families and Teachers } \\
(\text { LIFT })^{50,51,66}\end{array}$ & $\begin{array}{l}\mathrm{n}=67 \mathrm{I} \text { and } 35 \mathrm{I} \text {. Youth were } \\
\text { in grades five through } 12 \text {, } \\
\text { primarily white }\end{array}$ & $\begin{array}{l}\text { RCTs. Pre-/post-treatment, } \\
\text { I- and 3-year follow-ups; } \\
\text { assessments in grades 5-12 }\end{array}$ & $\begin{array}{l}\text { Reduced behavioral problems and } \\
\text { increased prosocial behavior. LIFT was } \\
\text { more effective for reducing maternal } \\
\text { aversive behavior among mothers who } \\
\text { demonstrated higher (versus lower) levels } \\
\text { of aversive behavior at pre-treatment }\end{array}$ \\
\hline $\begin{array}{l}\text { Resourceful Adolescent } \\
\text { Program-Family } \\
\left(\text { RAP-F) }{ }^{59}\right.\end{array}$ & $\begin{array}{l}\mathrm{n}=260 \text {. Youth were primarily } \\
\text { Anglo-Saxon, female, from } \\
\text { low to middle socioeconomic } \\
\text { status families; ages } 12-15 \text { years } \\
\text { (average age 13) }\end{array}$ & $\begin{array}{l}\text { Pre-/post-treatment, 10-month } \\
\text { follow-up }\end{array}$ & $\begin{array}{l}\text { The family support program (RAP-F) was } \\
\text { not superior to the non-family-support } \\
\text { condition, and both treatment groups } \\
\text { evidenced fewer symptoms of depression } \\
\text { and hopelessness at post-treatment and } \\
\text { follow-up relative to controls }\end{array}$ \\
\hline
\end{tabular}

Abbreviation: RCT, randomized controlled trial.

Positive parent outcomes included reductions in poor parenting behaviors - such as parental rejection of the child, authoritarian parenting strategies, and physical punishment - as well as increased use of positive parent management strategies such as greater use of praise and effective discipline. ${ }^{46,47,49-52,55}$ However, one study found no impact of the prevention program on parental monitoring or consistent discipline. ${ }^{49}$ Parent-child dyadic interactions became more positive in response to universal preventions, and these changes were maintained at follow-ups. ${ }^{47,48}$ Parents in universal preventions also experienced increased knowledge regarding parenting of children at specific developmental stages. ${ }^{48}$ Reductions in parental mental health problems - including depression and distress ${ }^{47,48}$ and improvements in positive feelings - such as increased self-esteem and self-efficacy ${ }^{55}$ were also reported outcomes of universal programs - with some exceptions. ${ }^{54}$ Increased satisfaction with social support and parent satisfaction with the programs also were reported. ${ }^{47,48,55}$

Overall, evidence for the effectiveness of universal preventions is mixed - there were several positive findings, but also some null effects, as well as evidence that the universal prevention programs did not yield more beneficial effects compared with control conditions. ${ }^{53,54}$ Some evidence indicated that universal preventions may only be effective $\mathrm{e}^{26,56}$ or may be especially effective $e^{50,51,58}$ for reducing mental and behavioral health problems among children displaying the highest levels of mental health issues. This interaction effect suggests that targeting interventions for youth who are at risk for mental and behavioral health problems may be a more efficient and productive strategy. ${ }^{60}$ More targeted preventative programs - selective preventions - will be reviewed next.

\section{Selective family support prevention programs}

Selective preventions focus on early identification of individuals at high risk for developing a disorder due to experiencing environmental or psychosocial risk factors for the disorder. The majority of family support prevention programs are selective. ${ }^{3}$ The selective family support prevention programs included in this review are described in Table 5. Outcomes for divorcing parents included improved communication, ${ }^{61}$ reductions in conflict, ${ }^{62,63}$ and reductions in interjecting the child in the parent's conflict, ${ }^{61}$ but also increases in ${ }^{64}$ and null effects on conflict. ${ }^{61}$ Additionally, female - but not male - ex-spouses perceived improved ability to 


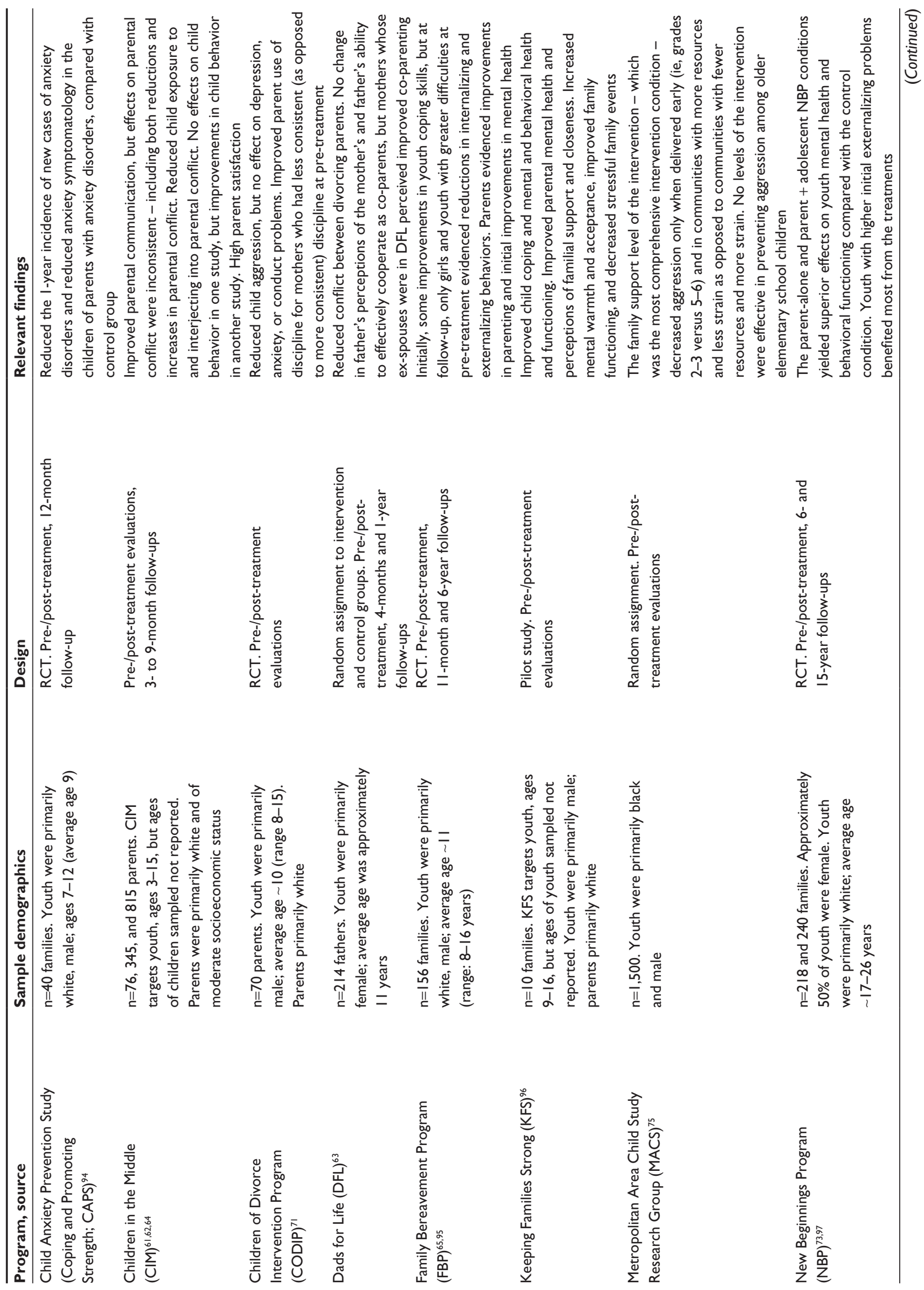




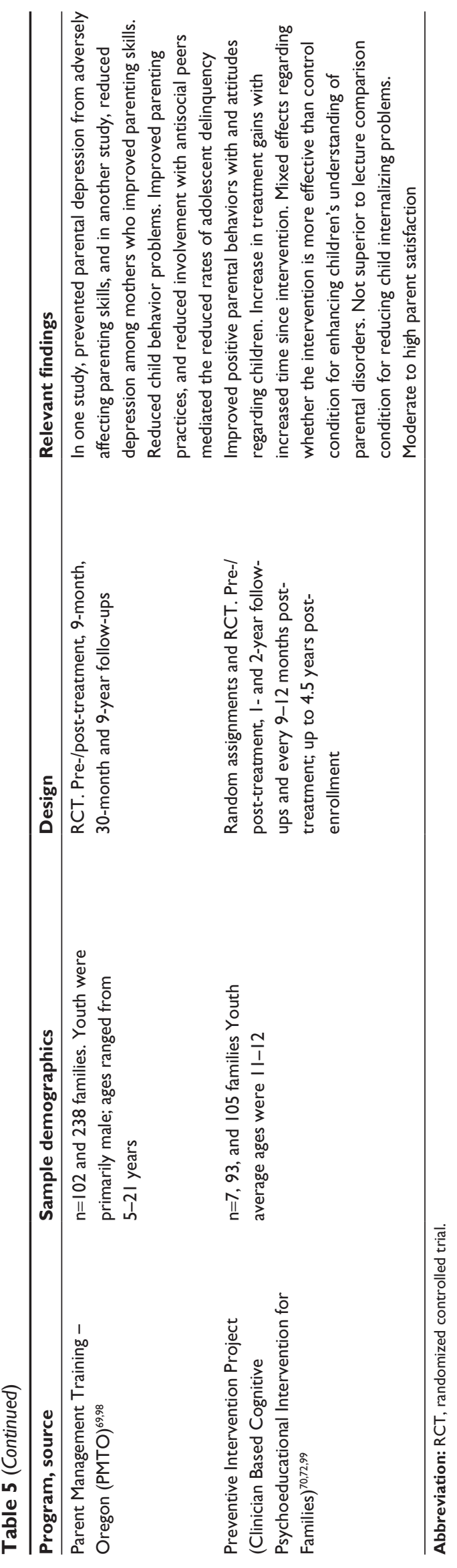

effectively cooperate as co-parents. ${ }^{63}$ Other studies yielded improvements in parenting, ${ }^{65,66}$ improvements in mental health (although in one study, improved mental health was not maintained at follow-up) ${ }^{65-68}$ prevention of mental health problems interfering with parenting ${ }^{69}$ increased perceived familial support and closeness and better family functioning, ${ }^{67}$ with an exception. ${ }^{70}$ In one study, an interaction effect was found such that parental discipline improved for mothers who demonstrated more inconsistent (as opposed to less inconsistent, or more consistent) discipline at pretreatment ${ }^{71}$ - adding to the accumulation of findings that program effects are stronger among high-risk participants. Another study reported improved parental behaviors with, and attitudes regarding children, and these gains increased with time since the intervention. ${ }^{70}$ Parent satisfaction with treatments was also reported. ${ }^{62,72}$

Child outcomes were more mixed - including reductions in ${ }^{62,68,71}$ and no effects on ${ }^{64,71}$ child behavior problems, no effects on child internalizing problems, ${ }^{68,71}$ but improved child coping and mental and behavioral health and functioning. $67,73,74$ In several studies, reductions in internalizing and externalizing problems were only experienced among youth at higher risk for, or experiencing the greatest difficulties with, these problems pre-treatment. ${ }^{65,71,75}$

Similar to the evidence for universal preventions, the evidence for the effectiveness of selective preventions is also mixed. Selective preventions yielded more beneficial effects for parents than children, although effects on conflict between divorcing parents was mixed. For children, both improvements in and null effects on internalizing and externalizing problems were found. In keeping with the theme of findings from other programs in this review, selective prevention effects were sometimes only found among families with the worst pre-treatment level of functioning - again, suggesting the increased efficacy of interventions for individuals at highest risk.

\section{Indicated family support prevention programs}

Indicated preventions target youth displaying minimal but noticeable symptoms of mental or behavioral health disorders suggesting the possibility of developing a clinical disorder in the future, although diagnostic criteria is not met at the time prevention is enacted. ${ }^{16}$ The indicated family support prevention programs included in this review are described in Table 6. Child outcomes from the indicated preventions were generally positive, although outcomes from some programs were inconsistent. Beneficial child effects included significant 
Table 6 Indicated preventions programs

\begin{tabular}{|c|c|c|c|}
\hline Program, source & Sample demographics & Design & Relevant findings \\
\hline $\begin{array}{l}\text { Cognitive Behavioral } \\
\text { Interventions for Trauma in } \\
\text { Schools (CBITS) }{ }^{79-81}\end{array}$ & $\begin{array}{l}\mathrm{n}=48,126, \text { and } 198 . \text { Youth } \\
\text { average age } \sim 1 \text { I years }\end{array}$ & $\begin{array}{l}\text { Pre-/post-treatment, } \\
\text { 3-month follow-up }\end{array}$ & $\begin{array}{l}\text { Reduced PTSD symptoms, depression, } \\
\text { and psychosocial dysfunction compared } \\
\text { with wait-list control. Greater decrease } \\
\text { in PTSD and depression symptoms } \\
\text { among intervention group youth with } \\
\text { clinically significant levels of PTSD } \\
\text { or depression at pre-treatment. No } \\
\text { difference between treatment and } \\
\text { control groups in acting out behavior, } \\
\text { shyness, or learning difficulties }\end{array}$ \\
\hline $\begin{array}{l}\text { Coping Power Program } \\
(\mathrm{CPP})^{82-84}\end{array}$ & $\begin{array}{l}\mathrm{n}=183-245 . \text { Youth were } \\
\text { primarily black or white, male, } \\
\text { fourth and fifth graders }\end{array}$ & $\begin{array}{l}\text { Pre-/mid-/post-treatment, } \\
\mathrm{I} \text { - and 3-year follow-ups }\end{array}$ & $\begin{array}{l}\text { Improved youth behavior and parenting, } \\
\text { especially for more comprehensive CPP } \\
\text { interventions }\end{array}$ \\
\hline $\begin{array}{l}\text { Early Risers "Skills for } \\
\text { Success" } 85\end{array}$ & $\begin{array}{l}\mathrm{n}=125 \text {. Early Risers targets } \\
\text { youth, ages } 6-12 \text { years, but this } \\
\text { study included fourth-graders } \\
\text { with average age } \sim 6 \text { years. } \\
\text { Youth were primarily male }\end{array}$ & RCT. 4-year follow-up & $\begin{array}{l}\text { Higher levels of prosocial functioning } \\
\text { compared with controls }\end{array}$ \\
\hline $\begin{array}{l}\text { Penn Resiliency Program } \\
(\text { PRP })^{76-78}\end{array}$ & $\begin{array}{l}\mathrm{n}=293-693 . \text { Youth were ages } \\
\text { I I-13 years, primarily male, } \\
\text { white or Australian }\end{array}$ & $\begin{array}{l}\text { RCTs. I8-month to 3-year } \\
\text { follow-ups }\end{array}$ & $\begin{array}{l}\text { Mixed effects, and weak support. Often } \\
\text { no effect on depression, anxiety, or } \\
\text { social skills. In one study, improvements } \\
\text { in explanatory style (associated with } \\
\text { depression) at 2-year follow-up. More } \\
\text { effective for preventing internalizing } \\
\text { and adjustment disorders among girls } \\
\text { and individuals with elevated initial } \\
\text { symptoms }\end{array}$ \\
\hline $\begin{array}{l}\text { Queensland Early Intervention } \\
\text { and Prevention Anxiety } \\
\text { Project (QEIPAP) }\end{array}$ & $\begin{array}{l}\mathrm{n}=128 . \text { Youth were ages } 7-\mid 4 ; \\
\text { primarily white }\end{array}$ & $\begin{array}{l}\text { RCT. 6-, I2-, and } \\
\text { 24-month follow-ups }\end{array}$ & $\begin{array}{l}\text { Inconsistent effects on reducing } \\
\text { incidence and prevalence of anxiety } \\
\text { disorders over time - eg, QEIPAP not } \\
\text { superior to control post-treatment, but } \\
\text { treatment gains emerged at 6-month } \\
\text { and 2-year follow-ups }\end{array}$ \\
\hline
\end{tabular}

Abbreviations: PTSD, posttraumatic stress disorder; RCT, randomized controlled trial.

improvements in youth mental and behavioral health and social functioning, ${ }^{76-85}$ with some exceptions of no effects on mental health or behavioral or social functioning. ${ }^{76,78,86,87}$ Two studies noted greater benefits of the indicated preventions among youth at higher risk for, or experiencing more, mental health problems at pre-treatment ${ }^{78,81}$ - consistent with the pattern of findings suggesting that treatments targeting high-risk groups may be more efficient.

Parent outcomes were less studied among indicated programs compared with universal and selective preventions. ${ }^{3}$ Among those indicated intervention studies that assessed parenting outcomes, results were positive - and suggested improvements in positive parenting and use of effective discipline strategies. ${ }^{82}$

The evidence for indicated family support preventions was generally favorable. Child outcomes included reductions in both internalizing and externalizing problems, as well as improvements in the cognitive mechanisms contributing to depression - in line with the principle of prevention to target factors implicated in the development and maintenance of disorders. Two of the three instructional-support-only indicated programs yielded inconsistent findings, while results of the third instructional-support-only indicated program were consistently positive. Given that the majority of instructionalsupport-only indicated programs produced inconsistent results relative to programs that combined multiple forms of support, it is possible that providing only one form of support - which may not be helpful to all clients - is not as effective as providing multiple forms of support that are more likely to impact many. Across all of the indicated programs, parent outcomes were not well studied, and the only parent outcomes studied were parenting strategies - parental wellbeing and mental health were not evaluated. Despite the lack of attention to parenting outcomes among indicated programs, 
parental outcomes that were addressed showed beneficial effects of the indicated programs.

\section{Multilevel family support prevention programs}

Multilevel family support prevention programs integrate assessment and prevention to maximize beneficial outcomes. With multilevel family support preventions, the intensity and nature of the prevention strategies provided may be adjusted depending on an individual's responsiveness. Multilevel family support preventions are as common as indicated preventions and - like indicated preventions - were relatively rare compared with universal and selective programs. ${ }^{3}$ The multilevel family support prevention programs included in this review are described in Table 7. Beneficial child outcomes associated with multilevel family support preventions included reductions in externalizing behavior ${ }^{88,89}$ and internalizing problems, ${ }^{90}$ as well as improved prosocial behavior. ${ }^{88}$ Participation in more intensive prevention levels accounted for two programs' beneficial effects, ${ }^{90,91}$ and one study reported an interaction effect wherein intervention participants at highest initial risk evidenced reductions in diagnoses and behavioral symptoms. ${ }^{92}$
Similar to indicated preventions, parent outcomes were not a primary focus of studies testing multilevel family support preventions. However, parenting outcomes reported were positive, and included improvements in mental health and parenting skills. ${ }^{88}$ Additionally, an interaction effect was found wherein parents in a more intensive prevention level experienced reductions in the use of over-reactive parenting strategies ${ }^{91}$ - again suggesting that greater intensity of intervention may be helpful.

Multilevel prevention programs appeared to be highly effective. Positive child outcomes primarily included reductions in externalizing behavior and involvement with antisocial peers. The reduction in involvement with antisocial peers is in line with the aim of prevention programs to alter causal mechanisms contributing to disorder. Although parent outcomes received less attention, positive caregiver outcomes included both mental health improvements as well as improvements in parenting behavior and skills.

\section{Prevention effectiveness summary}

Overall, prevention programs appear to be effective although effectiveness varies both across levels of prevention, and within levels across specific prevention programs. Multilevel programs and indicated preventions yielded

Table 7 Multilevel preventions programs

\begin{tabular}{|c|c|c|c|}
\hline Program, source & Sample demographics & Design & Relevant findings \\
\hline $\begin{array}{l}\text { Adolescent Transition } \\
\text { Program (ATP) }{ }^{90}\end{array}$ & $\begin{array}{l}\mathrm{n}=106 . \text { Youth were primarily black } \\
\text { and female; assessed in 6th-9th } \\
\text { grades }\end{array}$ & $\begin{array}{l}\text { RCT. Three-yearly } \\
\text { assessments }\end{array}$ & $\begin{array}{l}\text { ATP prevented escalations in } \\
\text { depressive symptoms. Intervention } \\
\text { effect was driven by participation in the } \\
\text { selected and indicated levels of ATP }\end{array}$ \\
\hline Fast Track $^{92}$ & $\begin{array}{l}\mathrm{n}=891 \text {. Youth were primarily black; } \\
\text { average age } \sim 6 \text { years. Ten-year } \\
\text { intervention (through grade } 9 \text { ) }\end{array}$ & $\begin{array}{l}\text { RCT. Assessments after } \\
\text { grades } 3,6 \text {, and } 9\end{array}$ & $\begin{array}{l}\text { Intervention participants at highest } \\
\text { initial risk evidenced reductions in } \\
\text { diagnoses and behavioral symptoms }\end{array}$ \\
\hline Incredible Years ${ }^{88}$ & $\begin{array}{l}\mathrm{n}=18 \text { families. Youth were primarily } \\
\text { black, female; ages } 5-12 \text { (average } \\
\text { age } 8 \text { ) }\end{array}$ & $\begin{array}{l}\text { Pilot study. Pre-/post- } \\
\text { treatment }\end{array}$ & $\begin{array}{l}\text { Reduced youth behavioral problems, } \\
\text { improved prosocial behaviors, } \\
\text { improved parental depression and } \\
\text { parenting skills (laxness, over-reactivity } \\
\text { and verbosity) }\end{array}$ \\
\hline $\begin{array}{l}\text { Teen Triple } \mathrm{P}-\text { Positive } \\
\text { Parenting Program }\end{array}$ & $\begin{array}{l}\mathrm{n}=280 . \text { Youth were primarily male; } \\
\text { ages } 8-13 \text { (average age } 10 \text { years), } \\
\text { from families with income below } \\
\text { the poverty line }\end{array}$ & $\begin{array}{l}\text { No control group. Pre-/ } \\
\text { post-treatment evaluations }\end{array}$ & $\begin{array}{l}\text { Fewer adolescent behavior problems } \\
\text { and less use of over-reactive parenting } \\
\text { strategies in more intensive Teen } \\
\text { Triple P level compared with the less } \\
\text { intensive level and waitlist control } \\
\text { conditions }\end{array}$ \\
\hline Raising Healthy Children ${ }^{89}$ & $\begin{array}{l}\mathrm{n}=959 . \text { Youth were primarily white } \\
\text { and male. Study began when youth } \\
\text { were average age } \sim 7 \text { years, in } \\
\text { Ist and } 2 \text { nd grades. Intervention } \\
\text { implemented through high school; } \\
\text { outcomes assessed during 6th-10th } \\
\text { grades (early to mid-adolescence) }\end{array}$ & Matched random assignment & $\begin{array}{l}\text { Reduced growth in frequency of } \\
\text { alcohol and marijuana use, but no } \\
\text { effect on use versus non-use }\end{array}$ \\
\hline
\end{tabular}

Abbreviation: RCT, randomized controlled trial. 
more consistently positive results than the less intensive preventative interventions - selective and universal. Findings from studies that evaluated whether increased intensity of preventions improved outcomes are in line with a body of other evidence suggesting that increasingly intensive and comprehensive levels of prevention are more effective than less intense preventative measures. Another consistent finding across prevention levels was that individuals with elevated levels of mental and behavioral health problems experienced better outcomes compared with individuals less in need of the services. This suggests that it may be more efficient for prevention efforts to target individuals at high-risk for mental and behavioral health problems than to target the entire population - as in universal prevention strategies. It is possible that more consistently positive evidence was found among indicated and multilevel preventions simply because there were fewer of these programs than the universal and selective preventions. Overall - across all prevention levels - parent outcomes were less studied than child outcomes. Parent outcomes primarily included improvement in parenting strategies, but some studies also focused on parental mental health and wellbeing. In terms of child outcomes, reductions in externalizing behavior were most common, followed by improvements in mental health and internalizing problems such as anxiety and depression, and only a few studies noted improvements in prosocial behavior such as social competence.

\section{Overall summary}

Family support programs demonstrated some effectiveness in improving caregiver mental health and parenting strategies as well as enhancing child mental and behavioral health. Among treatment programs, clinician-led programs that provided a combination of instructional, informational, and advocacy support demonstrated the most effectiveness. Peer-led programs had the weakest research base and least effectiveness. More research is needed to investigate the efficacy of peer-led programs given that parents/veteran parents who typically lead peer-led programs can serve as important supports and mentors for parents enrolled in the family support programs. ${ }^{2}$ Among prevention programs, multilevel and indicated programs demonstrated greater levels of effectiveness compared with the lower-level - universal and selective - preventions. Across all programs reviewed, those that included the most diverse forms of support were the most effective. Combining different forms of support may be useful, because different clients may need different forms of support and approaches. The evidence reviewed here suggests that when family support programs are riveted to providing one form of support, their effectiveness is limited. In other words, being rigid in the provision of support can shut out potential solutions to meeting each family's needs. For instance, multilevel prevention programs can improve the ability to select the best forms of support and tailor them for individual clients and presenting concerns. While all family support programs need not provide every form of support, it may be beneficial for family support programs to be open to using forms of support other than the primary form to enhance effectiveness and efficiency.

\section{Disclosure}

The authors report no conflicts of interest in this work.

\section{References}

1. Johnson MH, George P, Armstrong MI, et al. Behavioral management for children and adolescents: assessing the evidence. Psychiatr Serv. 2014;65(5):580-590.

2. Hoagwood K, Cavaleri M, Serene Olin S, et al. Family support in children's mental health: a review and synthesis. Clin Child Fam Psychol Rev. 2010;13(1):1-45.

3. Cavaleri MA, Serene OS, Kim A, Hoagwood KE, Burns BJ. Family support in prevention programs for children at risk for emotional/behavioral problems. Clin Child Fam Psychol Rev. 2011;14(4):399-412.

4. Houtrow AJ, Okumura MJ. Pediatric mental health problems and associated burden on families. Vulnerable Child Youth Stud. 2011;6:222-233.

5. Glied S, Pine DS. Consequences and correlates of adolescent depression. Arch Pediatr Adolesc Med. 2002;156:1009-1014.

6. Glatz T, Stattin H. Exploring parents' experiences and reactions to adolescents' hyperactivity, impulsivity, and attention problems. J Marriage Fam. 2013;75(4):1030-1043.

7. Rengasamy M, Mansoor BM, Hilton R, et al. The bi-directional relationship between parent-child conflict and treatment outcome in treatment-resistant adolescent depression. $J$ Am Acad Child Adolesc Psychiatry. 2013;52:370-377.

8. Wilkinson PO, Harris C, Kelvin R, Dubicka B, Goodyer IM. Associations between adolescent depression and parental mental health, before and after treatment of adolescent depression. Eur Child Adolesc Psychiatry. 2013;22:3-11.

9. Schuck K, Otten R, Engels RCME, Barker ED, Kleinjan M. Bidirectional influences between parents and children in smoking behavior: a longitudinal full-family model. Nicotine Tob Res. 2013;15:44-51.

10. Bronfenbrenner U, Morris PA. The bioecological model of human development. In: Damon W, Lerner RM, editors. Handbook of Child Psychology, Vol. 1: Theoretical Models of Human Development. 6th ed. New York, NY: Wiley; 2006:793-828.

11. Chu PS, Saucier DA, Hafner E. Meta-analysis of the relationships between social support and well-being in children and adolescents. J Soc Clin Psychol. 2010;29:624-625.

12. Compas BE, Wagner BM, Slavin LA, Vannatta K. A prospective study of life events, social support, and psychological symptomatology during the transition from high school to college. Am J Community Psychol. 1986;14:241-257.

13. Costa NM, Weems CF, Pellerin K, Dalton R. Parenting stress and childhood psychopathology: an examination of specificity to internalizing and externalizing symptoms. $J$ Psychopathol Behav Assess. 2006;28: $113-122$.

14. Deater-Deckard K. Parenting stress and child adjustment: some old hypotheses and new questions. Clin Psychol (New York). 1998;5: 314-332. 
15. Hadley W, Hunter HL, Tolou-Shams M, et al. Monitoring challenges: a closer look at parental monitoring, maternal psychopathology, and adolescent sexual risk. J Fam Psychol. 2011;25:319-323.

16. O'Connell ME, Boat T, Warner KE, editors. Defining the scope of prevention. In: Preventing Mental, Emotional, and Behavioral Disorders among Young People: Progress and Possibilities. Washington, DC: National Academies Press; 2009:59-69.

17. Dunst CJ, Trivette CM, Thompson RB. Supporting and strengthening family functioning: toward a congruence between principles and practice. Prev Hum Serv. 1991;9(1):19-43.

18. Valderhaug R, Larsson B, Gotestam KG, Piacentini J. An open clinical trial of cognitive-behaviour therapy in children and adolescents with obsessive-compulsive disorder administered in regular outpatient clinics. Behav Res Ther. 2007;45(3):577-589.

19. Walker SC, Pullman MD, Trupin EW. Juvenile Justice 101: addressing family support needs in juvenile court. J Juv Justice. 2012;2(1):54-72.

20. Kutash K, Duchnowski A, Green A, Ferron J. Supporting parents who have youth with emotional disturbances through a parent-to-parent support program: a proof of concept study using random assignment. Adm Policy Ment Health. 2011;38(5):412-427.

21. Kutash K, Duchnowski A, Green A, Ferron J. Effectiveness of the Parent Connectors Program: results from a randomized controlled trial. School Ment Health. 2013;5(4):192-208.

22. Brister T, Cavaleri MA, Olin SS, Shen S, Burns BJ, Hoagwood KE. An evaluation of the NAMI basics program. J Child Fam Stud. 2012;21:439-442.

23. Acri M, Frank S, Olin SS, et al. Examining the feasibility and acceptability of a screening and outreach model developed for a peer workforce. J Child Fam Stud. 2013:1-10.

24. Chronis AM, Gamble SA, Roberts JE, Pelham WE. Cognitivebehavioral depression treatment for mothers of children with attentiondeficit/hyperactivity disorder. Behav Ther. 2006;37(2):143-158.

25. Lipman EL, Boyle MH, Cunningham C, et al. Testing effectiveness of a community-based agression management program for children 7 to 11 years old and their families. J Am Acad Child Adolesc Psychiatry. 2006;45(9):1085-1093.

26. Barrett P, Healy-Farrell L, March JS. Cognitive-behavioral family treatment of childhood obsessive-compulsive disorder: a controlled trial. J Am Acad Child Adolesc Psychiatry. 2004;43(1):46-62.

27. McKay M, Stoewe J, McCadam K, Gonzales J. Increasing access to child mental health services for urban children and their caregivers. Health Soc Work. 1998;23(1):9-15.

28. Shortt AL, Barrett PM, Fox TL. Evaluating the FRIENDS Program: a cognitive-behavioral group treatment for anxious children and their parents. J Clin Child Psychol. 2001;30(4):525-535.

29. Kendall PC, Hudson JL, Gosch E, Flannery-Schroeder E, Suveg C. Cognitive-behavioral therapy for anxiety disordered youth: a randomized clinical trial evaluating child and family modalities. J Consult Clin Psychol. 2008;76(2):282-297.

30. Melvin GA, Tonge BJ, King NK, Heyne D, Gordon MS, Klimkeit EI. A comparison of cognitive-behavioral therapy, sertraline, and their combination for adolescent depression. J Am Acad Child Adolesc Psychiatry. 2006;45(10):1151-1161.

31. Cobham VE, Dadds MR, Spence SH. The role of parental anxiety in the treatment of childhood anxiety. J Consult Clin Psychol. 1998;66(6):893-905.

32. Cohen JA, Deblinger E, Mannarino AP, Steer RA. A multisite, randomized controlled trial for children with sexual abuse-related PTSD symptoms. J Am Acad Child Adolesc Psychiatry. 2004;43(4): 393-402.

33. Cohen J, Mannarino AP. Disseminating and implementing traumafocused CBT in community settings. Trauma Violence Abuse. 2008;9(4):214-226.

34. Fristad MA, Gavazzi SM, Mackinaw-Koons B. Family psychoeducation: an adjunctive intervention for children with bipolar disorder. Biol Psychiatry. 2003;53(11):1000-1008.
35. McCleary L, Ridley T. Parenting adolescents with ADHD: evaluation of a psychoeducation group. Patient Educ Couns. 1999;38(1):3-10.

36. Pavuluri MN, Graczyk PA, Henrey DB, Carbray JA, Heidenriech J, Miklowitz DJ. Child- and family-focused cognitive-behavioral therapy for pediatric bipolar disorder: development and preliminary results. J Am Acad Child Adolesc Psychiatry. 2004;43(5):528-537.

37. Pfeffer CR, Jiang H, Kakuma T, Hwang J, Metsch M. Group intervention for children bereaved by the suicide of a relative. J Am Acad Child Adolesc Psychiatry. 2002;41(5):505-513.

38. Chacko A, Wymbs BT, Wymbs FA, et al. Enhancing Traditional Behavioral Parent Training for Single Mothers of Children with ADHD. J Am Acad Child Adolesc Psychiatry. 2009;38(2):206-218.

39. Sheridan A, Moore LM. Running groups for parents with schizophrenic adolescents: initial experiences and plans for the future. J Adolesc. 1991;14(1):1-16.

40. Geist R, Heinmaa M, Stephens D, Davis R, Katzman D. Comparison of family therapy and family group psychoeducation. Can J Psychiatry. 2000;45(2):173-178.

41. Hoagwood K, Rodriguez J, Burton G, Penn M, Olin S, Shorter P. Parents as change agents: the Parent Empowerment Program for parent advisors in New York state. The 22nd Annual Research Conference: a system of care for children's mental health: expanding the research base; 2009; Tampa, FL.

42. Koroloff NM, Elliott DJ. Linking low-income families to children's mental health services: an outcome study. J Emot Behav Disord. 1996;4(1):2.

43. Bickman L, Heflinger CA, Northrup D, Sonnichsen S, Schilling S. Long term outcomes to family caregiver empowerment. J Child Fam Stud. 1998;7(3):269-282.

44. McKay MM, Gonzales J, Quintana E, Kim L, Abdul-Adil J. Multiple family groups: an alternative for reducing disruptive behavioral difficulties of urban children. Res Soc Work Pract. 1999;9(5): 593-607.

45. Ruffolo MC, Kuhn MT, Evans ME. Support, empowerment, and education: a study of multiple family group psychoeducation. J Emot Behav Disord. 2005;13(4):200-212.

46. Myers HF, Alvy KT, Arrington A, et al. The impact of a parent training program on inner-city African-American families. J Community Psychol. 1992;20(2):132-147.

47. Niccols A. Immediate and short-term outcomes of the "COPEing with Toddler Behaviour" parent group. J Child Psychol Psychiatry. 2009;50(5):617-626.

48. Niccols A. An ounce of prevention: "COPEing with Toddler Behavior". Can J Psychiatry. 2004;49(12):869.

49. Ialongo N, Poduska J, Werthamer L, Kellam S. The distal impact of two first-grade preventive interventions on conduct problems and disorder in early adolescence. J Emot Behav Disord. 2001;9(3):146-160.

50. Reid JB, Eddy JM, Fetrow RA, Stoolmiller M. Description and immediate impacts of a preventive intervention for conduct problems. Am J Community Psychol. 1999;27(4):483-517.

51. Eddy JM, Reid JB, Fetrow RA. An elementary school-based prevention program targeting modifiable antecedents of youth delinquency and violence: linking the interests of families and teachers (LIFT). J Emot Behav Disord. 2000;8(3):165-176.

52. DeGarmo DS, Forgatch MS. Early development of delinquency within divorced families: Evaluating a randomized preventive intervention trial. Dev Sci. 2005;8(3):229-239.

53. Cheng S, Kondo N, Aoki Y, Kitamura Y, Takeda Y, Yamagata Z. The effectiveness of early intervention and the factors related to child behavioral problems at age 2: a randomized controlled trial. Early Hum Dev. 2007;83(10):683-691.

54. Hiscock H, Bayer JK, Price A, Ukoumunne OC, Rogers S, Wake M. Universal parenting programme to prevent early childhood behavioural problems: cluster randomised trial. BMJ. 2008;336(7639): 318-321.

55. Miller-Heyl J, MacPhee D, Fritz JJ. DARE to be you: a family-support, early prevention program. J Prim Prev. 1998;18(3):257-285. 
56. Lowry-Webster HM, Barrett PM, Dadds MR. A universal prevention trial of anxiety and depressive symptomatology in childhood: preliminary data from an Australian study. Behav Change. 2001;18(1): 36-50.

57. Aronen ET, Kurkela SA. Long-term effects of an early home-based intervention. J Am Acad Child Adolesc Psychiatry. 1996;35(12): 1665-1672.

58. Aronen ET, Arajarvi T. Effects of early intervention on psychiatric symptoms of youth adults in low-risk and high-risk families. $\mathrm{Am} J$ Orthopsychiatry. 2000;70(2):223-232.

59. Shochet IM, Dadds MR, Holland D, Whitefield K, Harnett PH, Osgarby SM. The efficacy of a universal schoolbased program to prevent adolescent depression. J Clin Child Psychol. 2001;30(3):303-315.

60. Roe E, Becker J. Drug prevention with vulnerable young people: a review. Drugs Educ Prev Policy. 2005;12:85-99.

61. Kramer KM, Arbuthnot J, Gordon DA, Roussis N, Hoza J. Effects of skill-based vs information-based divorce education programs on domestic violence and parental communication. Fam Court Rev 1998;36(1):9-31.

62. Gillard L, Seymour F. Children in the Middle: A Parent Education Programme for Separated Parents. Auckland, New Zealand: Department of Psychology, University of Auckland; 2005. Available from www. divorce-education.com/media/uploads/research/Programme.pdf. Accessed June 23, 2014.

63. Cookston JT, Braver SL, Griffin WA, de Lusé SR, Miles JC. Effects of the Dads for Life Intervention on Interparental Conflict and Coparenting in the Two Years After Divorce. Fam Process. 2007;46(1):123-137.

64. Brandon DJ. Can four hours make a difference? Evaluation of a parent education program for divorcing parents. J Divorce Remarriage. 2006;45(1-2):171-185.

65. Sandler IN, Ayers TS, Wolchik SA, et al. The Family Bereavement Program: efficacy evaluation of a theory-based prevention program for parentally bereaved children and adolescents. J Consult Clin Psychol. 2003;71(3):587-600.

66. DeGarmo DS, Eddy JM, Reid JB, Feetrow RA. Evaluating mediators of the impact of the Linking the Interests of Families and Teachers (LIFT) multimodal preventive intervention on substance use initiation and growth across adolescence. Prev Sci. 2009; 10:208-220.

67. Riley AW, Valdez CR, Barrueco S, et al. Development of a family-based program to reduce risk and promote resilience among families affected by maternal depression: theoretical basis and program description. Clin Child Fam Psychol Rev. 2008;11(1-2):12-19.

68. Patterson GR, DeGarmo D, Forgatch MS. Systematic changes in families following prevention trials. J Abnorm Child Psychol. 2004;32(6):621-633.

69. Sigmarsdóttir M, Degarmo DS, Forgatch MS, Guðmundsdóttir EV. Treatment effectiveness of PMTO for children's behavior problems in Iceland: assessing parenting practices in a randomized controlled trial. Scand J Psychol. 2013;54(6):468-476.

70. Beardslee WR, Gladstone TRG, Wright EJ, Cooper AB. A family-based approach to the prevention of depressive symptoms in children at risk: evidence of parental and child change. Pediatrics. 2003;112:119-131.

71. Wolchik SA, West SG, Westover S, et al. The Children of Divorce Parenting Intervention: outcome evaluation of an empirically based program. Am J Community Psychol. 1993;21(3):293-331.

72. Beardslee WR, Hoke L, Wheelock I, Rothberg PC, van de Velde P, Swatling S. Initial findings on preventive intervention for families with parental affective disorders. Am J Psychiatry. 2002;149: 1335-1340.

73. Wolchik SA, Sandler IN, Millsap RE, Plummer BA, Greene SM, Anderson ER. Six-year follow-up of preventive interventions for children of divorced: a randomized controlled trial. JAMA. 2002;288(15):1873-1881.

74. Wolchik SA, Schenck CE, Sandler IN. Promoting resilience in youth from divorced families: lessons learned from experimental trials of the New Beginnings Program. J Pers. 2009;77(6):1833-1868.
75. Metropolitan Area Child Study Research Group. A cognitive/ ecological approach to preventing aggression in economically disadvantaged urban settings: preliminary outcomes. J Consult Clin Psychol. 2002;70:179-194.

76. Gillham JE, Reivich KJ, Freres DR, Chaplin TM, Shatte AJ, Samuels B. School-based prevention of depressive symptoms: a randomized controlled study of the effectiveness and specificity of the Penn Resiliency Program. J Consult Clin Psychol. 2007;75(1):9-19.

77. Gillham JE, Hamilton J, Freres DR, Patton K, Gallop R. Preventing depression among early adolescents in the primary care setting: a randomized controlled study of the Penn Resiliency Program. J Abnorm Child Psychol. 2006;34(2):203-219.

78. Roberts C, Kane R, Bishop B, Matthews H, Thomson H. The prevention of depressive symptoms in rural school children: a follow-up study. Int J Ment Health Promot. 2004;6(3):4-16.

79. Morsette A, Swaney G, Stolle D, Schuldberg D, van den Pol R, Young M. Cognitive behavioral intervention for trauma in schools (CBITS): school-based treatment on a rural American Indian reservation. J Behav Ther Exper Psychiatry. 2009;40:169-178.

80. Stein BD, Jaycox LH, Kataoka SH, Wong M, Tu W, Elliott MN. A mental health intervention for school children exposed to violence: a randomized controlled trial. JAMA. 2003;290(5):603-611.

81. Kataoka SH, Stein BD, Jaycox LH, et al. A school-based mental health program for traumatized Latino immigrant children. J Am Acad Child Adolesc Psychiatry. 2003;42(3):311-318.

82. Lochman JE, Wells KC. Effectiveness study of Coping Power and classroom intervention with aggressive children: outcomes at a one-year follow-up. Behav Ther. 2003;34(4):493-515.

83. Lochman JE, Wells KC. Contextual social-cognitive mediators and child outcome: a test of the theoretical model in the Coping Power Program. Dev Psychopathol. 2002;14:971-993.

84. Lochman JE, Wells KC. The Coping Power program for preadolescent aggressive boys and their parents: outcome effects at the one-year follow-up. J Consult Clin Psychol. 2004;72(4):571-578.

85. August GJ, Egan EA, Realmuto GM, Hektner JM. Four years of the early risers early-age-targeted preventive intervention: effects on aggressive children's peer relations. Behav Ther. 2003;34(4): 453-470.

86. Dadds MR, Holland DE, Laurens KR, Mullins M, Barrett PM, Spence SH. Early intervention and prevention of anxiety disorders in children: results at 2-year follow-up. J Consult Clin Psychol. 1999;67(1):145-150.

87. Dadds MR, Spence SH, Holland D, Barrett PM, Laurens K. Early intervention and prevention of anxiety disorders: a controlled trial. J Consult Clin Psychol. 1997;65:627-635.

88. Hutchings J, Bywater T, Williams ME, Whitaker C, Lane E, Shakespeare K. The extended school aged Incredible Years parent programme. Child Adolesc Ment Health. 2011;16(3):136-143.

89. Brown EC, Catalano RF, Fleming CB, Haggerty KP, Abbott RD. Adolescent substance use outcomes in the Raising Healthy Children Project: a two-part latent growth curve analysis. J Consult Clin Psychol. 2005;73(4):699-710.

90. Connell AM, Dishion TJ. Reducing depression among at-risk early adolescents: three-year effects of a family-centered intervention embedded within schools. J Fam Psychol. 2008;22(4):574-585.

91. Stallman HM, Ralph A. Reducing risk factors for adolescent behavioural and emotional problems: a pilot randomised controlled trial of a self-administered parenting intervention. Adv Ment Health. 2007;6(2):125-137.

92. Dodge KA. Fast track randomized controlled trial to prevent externalizing psychiatric disorders: findings from grades 3 to 9. J Am Acad Child Adolesc Psychiatry. 2007;46(10):1250-1262.

93. Barrett PM, Lock S, Farrell LJ. Developmental differences in universal preventive intervention for child anxiety. Clin Child Psychol Psychiatry. 2005;10(4):539-555.

94. Ginsburg GS. The Child Anxiety Prevention Study: intervention model and primary outcomes. J Consult Clin Psychol. 2009;77(3): 580-587. 
95. Sandler IN, Ma Y, Tein JY, et al. Long-term effects of the Family Bereavement Program on multiple indicators of grief in parentally bereaved children and adolescents J Consult Clin Psychol. 2010;78(2): 131-143.

96. Valdez CR, Mills CL, Barrueco S, Leis J, Riley AW. A pilot study of a family-focused intervention for children and families affected by maternal depression. J Fam Ther. 2011;33(1):3-19.

97. Wolchik SA, Sandler IN, Tein J-Y, et al. Fifteen-year follow-up of a randomized trial of a preventive intervention for divorced families: effects on mental health and substance use outcomes in young adulthood. J Consult Clin Psychol. 2013;81(4):660-673.
98. Forgatch MS, Patterson GR, Degarmo DS, Beldavs ZG. Testing the Oregon delinquency model with 9-year follow-up of the Oregon Divorce Study. Dev Psychopathol. 2009;21(2):637-660.

99. Beardslee WR, Wright EJ, Gladstone TRG, Forbes P. Long-term effects from a randomized trial of two public health preventive interventions for parental depression. J Fam Psychol. 2007;21(4):703-713.

\section{Publish your work in this journal}

Adolescent Health, Medicine and Therapeutics is an international, peer-reviewed, open access journal focusing on health, pathology, and treatment issues specific to the adolescent age group. All aspects of health maintenance, preventative measures and disease treatment interventions are addressed within the journal and practitioners from all disciplines are invited to submit their work as well as healthcare researchers and patient support groups.. The manuscript management system is completely online and includes a very quick and fair peerreview system. Visit http://www.dovepress.com/testimonials.php to read real quotes from published authors.

Submit your manuscript here: http://www.dovepress.com/adolescent-health-medicine-and-therapeutics-journal 